\title{
Antibacterial Activity of Pseudoelephantopus spicatus (Juss) Rohr Extracts from the West Sub-catchment of Mt. Isarog Natural Park
}

\author{
NOEL QUIMING ${ }^{1 *}$, MARIBIE REYES MINOR ${ }^{1}$, MARIOUE NICOLAS ${ }^{1}$, \\ DHENNIS VERZOSA ${ }^{1}$ and MICHAEL RUSSELLE ALVAREZ ${ }^{2}$
}

\author{
${ }^{1}$ College of Arts and Science, University of the Philippines Manila, Padre Faura St., Ermita, \\ Manila City, Philippines.
}

2Institute of Chemistry, University of the Philippines Los Baños, Los Baños, Laguna, Philippines. ${ }^{*}$ Corresponding author E-mail: nsquiming@up.edu.ph

http://dx.doi.org/10.13005/ojc/350605

(Received: September 03, 2019; Accepted: December 06, 2019)

\begin{abstract}
The antibacterial activity of Pseudelephantopus spicatus (Juss) Rohr from the west sub-catchments of Mt. Isarog, Panicuason, Naga City Philippines were investigated. Samples of the plant were collected from wet (PSW-W) and dry (PSW-D) seasons. Ethanolic crude extracts obtained from air-dried leaves of PSW-W and PSW-D samples exhibited antibacterial activity against two Gram-positive bacteria (Micrococcus luteus and Staphylococcus aureus) and two Gram-negative bacteria (Escherichia coli and Enterobacter aerogenes). Assay-guided purification using normalphase column chromatography and subsequently preparative TLC yielded several active fractions that are bioactive(PSW-D-F-9 and PSW-W-D-13). Phytochemical screening by TLC revealed that the active fraction PSW-W-D-13 contains alkaloids, higher alcohols, phenols, steroids and essential oils while the active fraction PSW-D-F-9 contains tannins, flavonoids, alkaloids, higher alcohols, phenols, steroids and essential oils.
\end{abstract}

Keywords: Pseudoelephantopus spicatus, Antibacterial, Phytochemical, Purification.

\section{INTRODUCTION}

The development and emergent of infectious diseases is relatively alarming nowadays. Different pharmacological industries have produced a number of new antibiotics in the past years but still resistance of microorganisms to these drugs has increased. In general, bacteria have the genetic ability to transmit and acquire resistance to drugs utilized as therapeutic agents. Such a fact is a cause for concern, because of the number of patients in hospitals who have suppressed immunity, and due to new bacterial strains which are multi-resistant. Consequently, new infections can occur in hospitals resulting in high mortality ${ }^{1}$. The problem of microbial resistance is growing and the outlook for the use of antimicrobial drugs in the future is still uncertain. Therefore, actions must be taken to reduce this problem and develop appropriate and efficient antimicrobial drugs to patients.

This is an Open Access article licensed under a Creative Commons license: Attribution 4.0 International (CC- BY). Published by Oriental Scientific Publishing Company @ 2018

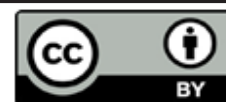


Mt. Isarog in Camarines Sur has become internationally recognized as one of the Philippine's most fragile and treasured centers of biological diversity. Surrounding communities depend heavily on the pristine forests of Mt. Isarog for clean drinking water, building materials, renewable forest resources such as rattan and palm, important sources of protein from low scale subsistence hunting, water for irrigation in nearby lowlands and medicinal plants ${ }^{2}$. These medicinal plants could be studied to help in the analysis of plant toxicity and protect human and animals from natural poison and can serve as resources of new drugs. Many of the modern medicines are produced indirectly from medicinal plants and an estimated 300,000 plant species have been studied ${ }^{3}$.

Pseudoelephantopus spicatus Juss (Rohr), locally known as dilang-aso in the Philippines, is a perennial herb, $10-40 \mathrm{~cm}$ tall ${ }^{4}$. The stems are acaulescent, erect, inconspicuously ribbed and puberulous. On the other hand, the leaves (5-15 by $1.5-5 \mathrm{~cm}$ ) are oblong-obovate, with a blunt tip and narrowed base. The capitulescences are terminal and axillary, with 1-4 capitula aggregated in clusters supported by narrowly linear foliaceous bracts. The phyllaries are light green $(6-12 \mathrm{~mm}$ long). It is an herbal medicine with many uses. In Philippine ethnobotanical medicine, $P$. spicatus leaves are used for the treatment of boils, decoction taken orally for coughs with blood, root decoction for diarrhea, and the whole plant for stomach ache ${ }^{5}$. In India, whole $P$. spicatus plants are used for snake envenomation ${ }^{6}$. The traditional Taiwanese medicine Teng-khia-u, which contains Elephantopus mollis H.B.K., E. scaber L. subsp. Oblanceolate Kitamura, and Pseudoelephantopus spicatus (Cass.) Aubl., is marketed and used as a treatment for hepatitis?. In Peru, the traditional medicine of the Chayahuita people use the dried leaves for skin ulcers ${ }^{8}$.

Due to the increasing number of newly discovered drugs mostly derived from plants, this accounts for the need to facilitate the drug discovery processes to develop new and effective screening methods from plant extracts to the isolation of its active components ${ }^{9}$. Previous studies have already proven bioactive compounds present on crude natural products and are identified using bioactivityguided fractionation and isolation. Such bioactive compounds are mostly plant secondary metabolites. Phytochemical screening encompasses various methods on how to examine the plant for these compounds to be isolated and be further modified to enhance their activity and biological profiles ${ }^{10}$.

In this study, the antibacterial properties of P. spicatus ethanolic leaf extracts from Mt. Isarog, Camarines Sur, Philippines were demonstrated against Gram-positive (M. luteus and S. aureus) and Gram-negative (E. coli and E. aerogenes) bacteria. Assay-guided fractionation and phytochemical characterization was undertaken to characterize the compounds present in the active fractions. To our knowledge, this is the first report of the antibacterial activity of $P$. spicatus from Mt. Isarog, Philippines.

\section{MATERIALS AND METHODS}

\section{Materials}

Technical grade ethanol from ChemLine Scientific Enterprises (Quezon City, Philippines) was used as the extraction solvent. Nutrient Agar, Nutrient Broth, Mueller Hinton Agar, Sabouraud Dextrose Agar and Isotonic Solution, purchased from HiMedia Laboratories Pvt. Limited (India) were used for the antibacterial and antifungal assays. Analytical grade solvents such as dimethyl sulfoxide (DMSO), hexane, chloroform, ethyl acetate, deionized water and methanol used in all the chromatographic methods were all purchased from LabScan Analytical Sciences (Bangkok, Thailand). The silica plates used for thin layer chromatography were TLC Silica gel 60 F254 obtained from Merck KGaA (Darmstadt, Germany). Silica gel 60 (0.063-0.200 mm, 60-230 mesh ASTM) by Merck® was used as the stationary phase in column chromatography.

\section{Plant sample and extraction}

The plant sample, P. spicatus (Juss) rohr, was previously acquired by the researchers from the western sub-catchment of Mt. Isarog Natural Park, Panicuason, Naga City, Camarines Sur, Philippines. Samples were collected during the wet (PSW-W) and dry (PSW-D) seasons. The collections were identified by Dr. Emelina G. Regis (Ateneo de Naga University, Bicol, Philippines) and later authenticated by Prof. Pat Malabrigo (University of the Philippines Los Baños, Laguna, Philippines). These were thoroughly air-dried, finely ground and soaked in technical grade $(95 \%)$ ethanol for about 48 hours. Extracts were dried in vacuo and kept at $5^{\circ} \mathrm{C}$ and stored in lightprotected containers to prevent photodecomposition of its bioactive components. 


\section{Antibacterial screening}

Antibacterial screening was tested on two Gram-positive bacteria-Micrococcus luteus and Staphylococcus aureus-and two Gram-negative bacteria-Escherichia coli and Enterobacter aerogenes.

Paper disc diffusion method was employed to determine the antibacterial activities of the crude plant extracts. Prior to the assay, bacteria were inoculated in nutrient broth $\left(24 \mathrm{~h}, 37^{\circ} \mathrm{C}\right)$. One-day old cultures were adjusted to McFarland Standard 1.5x108 CFU/ $\mathrm{mL}$. Then, the bacteria were inoculated onto petri dishes with Nutrient agar and inoculum of bacteria was then inoculated evenly in petri dishes containing Nutrient Agar using sterile cotton swabs. Paper discs containing $300 \mathrm{mg}$ of each sample as well as DMSO (negative control) and $10 \mathrm{mg} / \mathrm{mL}$ chloramphenicol (Gram-positive bacteria positive control) and $10 \mathrm{mg} /$ $\mathrm{mL}$ tetracycline (Gram-negative positive control) were prepared and placed on the petri dishes then incubated $\left(24-48 \mathrm{~h}, 37^{\circ} \mathrm{C}\right)$. Zones of inhibition were measured after the incubation period.

\section{Fractionation of PSW-W and PSW-D extracts using column chromatography}

Approximately one gram each of PSW-W and PSW-D samples were loaded into separate glass columns packed with silica gel. Fractions were eluted using step-gradient solvent system, from $100 \%$ ethyl acetate to $100 \%$ methanol. Eluents were collected every five milliliters $(5 \mathrm{~mL})$ then pooled together using TLC to produce five fractions from PSW-W and six fractions from PSW-D. These fractions were subjected to antibacterial assay to determine the most active fraction from PSW-W and PSW-D.

Purification of most active fractions (PSW-W-D and PSW-D-F) using preparative chromatography

Further purification of the most active fractions, PSW-W-D and PSW-D-F, was done by using preparative TLC (0.5-2.0 mm). Samples were spotted onto plates which were developed in hexane-ethyl acetate-methanol-water (1:1:1:1) for PSW-W active fraction and chloroform-watermethanol (18:1:1) for PSW-D active fraction. After prep TLC development, fractions were collected from the plates by marking the bands under UV light ( $365 \mathrm{~nm}$ and $254 \mathrm{~nm}$ ) then scraping off the silica. Compounds were eluted from the silica by dissolution in appropriate solvent and sonication. These collected fractions were again subjected to antibacterial assay to determine the most active compounds from PSW-W-D and PSW-D-F.

\section{Phytochemical analysis of most active fractions}

The most active fractions from the preparative thin layer chromatography were subjected to five phytochemical screening tests by thin layer chromatography ${ }^{11}$. Different qualitative tests for secondary metabolites-alkaloids, steroids, terpenoids, anthraquinones, flavonoids, saponins, tannins and polyphenols and cyanogenic glycosides were performed.

\section{Statistical analysis}

All assays were performed in triplicate $(n=3)$. To compare the antibacterial activities between treatments against each bacteria species, One-Way ANOVA with Tukey post-hoc test $(\alpha=0.05)$. To compare the antibacterial activities of the plant treatments compared to the positive control, One-Way ANOVA with Dunnett t (2-sided) post-hoc tests were performed $(\alpha=0.05)$.

\section{RESULTS}

\section{Antibacterial screening of crude extracts}

Both the ethanolic crude extracts of the dry and wet season samples exhibited antibacterial activity against two Gram-positive bacteria-M. Iuteus and S. aureus-and two Gram-negative bacteria E. coli and E. aerogenes. Inhibition of the crude extracts are presented in Table 1.

Table 1: Antibacterial Activity of Crude Ethanolic Extracts of Pseudelephantopus spicatus (Juss) Rohr from the west sub-catchments of Mt. Isarog Natural Park

\begin{tabular}{|c|c|c|c|c|}
\hline \multirow[t]{2}{*}{ Sample } & \multirow[b]{2}{*}{ E. coli } & \multicolumn{2}{|c|}{ Zone of Inhibition in $\mathrm{mm}(\mathrm{n}=3)$} & \multirow[b]{2}{*}{ M. luteus } \\
\hline & & E. aerogenes & S. aureus & \\
\hline DMSO (negative control) & No activity & No activity & No activity & No activity \\
\hline Positive Control $^{\circ}$ & $33.00 \pm 5.00$ & $31.67 \pm 4.15$ & $14.00 \pm 2.65$ & $27.67 \pm 3.00$ \\
\hline PSW-W Crude & $11.33 \pm 1.15$ & $11.00 \pm 2.65$ & $9.33 \pm 2.65$ & $16.00 \pm 0.58$ \\
\hline PSW-D Crude & $9.33 \pm 1.53$ & $12.00 \pm 4.58$ & $9.67 \pm 1.53$ & $10.33 \pm 1.15$ \\
\hline
\end{tabular}


The crude ethanolic extract from the wet season showed the strongest inhibition against M. luteus. dimethyl sulfoxide (DMSO), used for negative control exhibited no inhibition for all test organisms, therefore attributing the antibacterial activity to the extract alone. Neither extracts were found to be more active than the positive control. Nevertheless further purification, as discussed further, was able to enhance bioactivity.

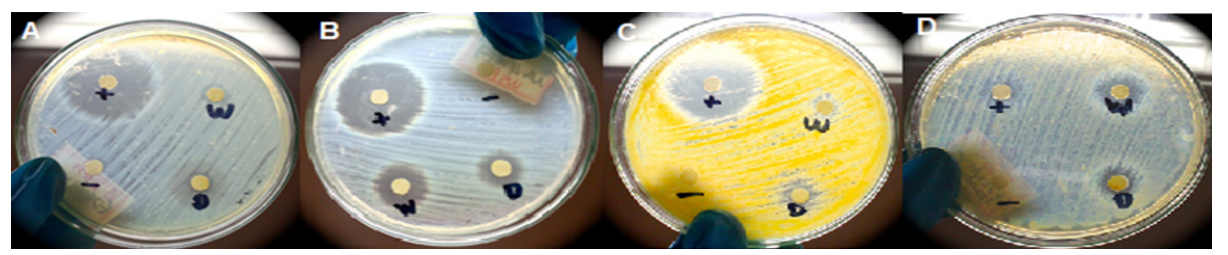

Fig. 1. Kirby-Bauer Assay Plates of Crude Ethanolic Extracts against E. coli (A), E. aerogenes (B), M. Iuteus (C) and S. aureus (D). For (A) and (B), the positive control contains $\mathbf{3 0 0} \mu \mathrm{g}$ of tetracycline while for (C) and (D) the positive control contains $300 \mu \mathrm{g}$ chloramphenicol. Negative control contains $300 \mu \mathrm{g}$ of DMSO. Discs labeled W and D contains $300 \mu \mathrm{g}$ PSW-W crude and PSW-D crude extracts, respectively

Antibacterial screening of column-purified fractions

Collected fractions with similarchromatographic profiles were pooled. Six pooled fractions were obtained for the dry sample and five for the wet sample. The pooled fractions were subjected to another round of antibacterial assays. Consistently, $M$. luteus was still the most susceptible among the test organisms. PSW-W-D exhibited the highest average activity for all test organisms in the wet samples and PSW-D-F with the greatest average activity for all samples.

Table 2. Antibacterial Activity of PSW-W and PSW-D Fractions

\begin{tabular}{lccccc}
\hline & \multirow{2}{*}{ Sample } & & \multicolumn{3}{c}{ Zone of Inhibition in mm (n=3) } \\
& & E. coli & E. aerogenes & M. luteus & S. aureus \\
\hline DMSO (negative control) & No activity & No activity & No activity & No activity \\
Positive Control & & $18.00 \pm 1.00$ & $22.17 \pm 3.00$ & $24.67 \pm 2.50$ & $19.50 \pm 1.00$ \\
PSW-W & PSW-W-A & N.A. & $6.33 \pm 0.58$ & $6.33 \pm 0.58$ & N.A. \\
& PSW-W-B & N.A. & $10.33 \pm 5.86$ & $6.67 \pm 0.58$ & $7.33 \pm 0.58$ \\
& PSW-W-C & $9.67 \pm 1.52$ & $12.00 \pm 6.00$ & $19.00 \pm 1.00$ & $5.67 \pm 5.13$ \\
& PSW-W-D & $10.67 \pm 2.08$ & $17.00 \pm 3.00$ & $20.67 \pm 2.31$ & $9.67 \pm 8.50$ \\
PSW-D & PSW-W-E & $8.33 \pm 0.58$ & $13.67 \pm 5.13$ & $18.67 \pm 0.58$ & $10.00 \pm 3.46$ \\
& PSW-D-A & $7.33 \pm 0.58$ & $8.67 \pm 1.52$ & $15.33 \pm 2.52$ & $9.67 \pm 4.73$ \\
& PSW-D-B & $6.67 \pm 0.58$ & $7.33 \pm 0.58$ & $12.00 \pm 3.00$ & $2.33 \pm 4.04$ \\
& PSW-D-C & $9.67 \pm 2.31$ & $10.67 \pm 5.03$ & $19.67 \pm 1.53$ & $14.00 \pm 2.00$ \\
& PSW-D-D & $6.67 \pm 1.15$ & $2.00 \pm 3.46$ & $7.00 \pm 1.00$ & N.A. \\
& PSW-D-E & N.A. & N.A. & $9.33 \pm 2.08$ & $8.00 \pm 7.00$ \\
& PSW-D-F & $14.00 \pm 3.46$ & $16.67 \pm 1.53$ & $19.33 \pm 1.15$ & $13.33 \pm 1.53$ \\
\hline
\end{tabular}

${ }^{\circ}$ Chloramphenicol $(10 \mathrm{mg} / \mathrm{mL})$ and tetracycline $(10 \mathrm{mg} / \mathrm{mL})$ were used as positive controls for Gram-positive and Gram-negative bacteria,respectively

PSW-W-D exhibited the highest activity for test organisms: E.coli, E. aerogenes and $M$. luteus and also the highest average zone of inhibition for all test organisms in comparison with other PSW-W fractions. Compared to the positive control, PSW-W-D had bioactivity that was not significantly different against $E$. Aerogenes $(p=0.828>0.05)$, M. Iuteus $(p=0.259>0.05)$, and $S$. aureus $(p=0.200>0.05)$. On the other hand, PSW-D-F showed the greatest activity in comparison with other PSW-D fractions against all test microorganisms. Furthermore, PSW-D-F was found to have bioactivity that is not significantly different than the positive control for E. Coli $(p=0.105>0.05)$, E. Aerogenes $(p=0.770>0.05)$, and $S$. aureus $(p=0.790>0.05)$. Thus, these fractions were chosen to be purified further using preparative TLC. 


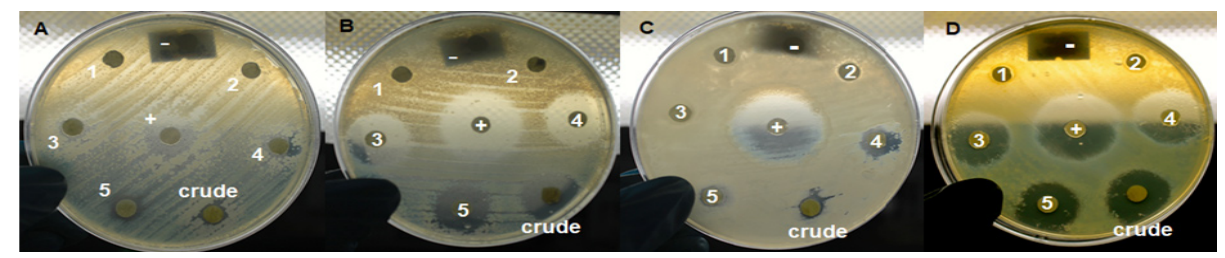

Fig. 2. Kirby-Bauer Assay Plates of Pooled Fractions of PSW-W fractions against E. coli (A), E. aerogenes (B), S. aureus (C), and M. luteus (D). For (A) and (B), the positive control contains $300 \mu \mathrm{g}$ of tetracycline while for (C) and (D) the positive control contains $300 \mu \mathrm{g}$ chloramphenicol. Negative control contains $300 \mu \mathrm{g}$ of DMSO. Each disc with extract and fraction contains $\mathbf{3 0 0} \mu \mathrm{g}$ sample

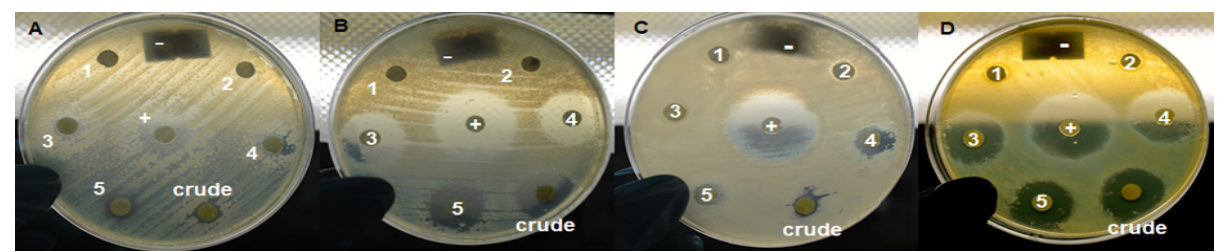

Fig. 3. Kirby-Bauer Assay Plates of Pooled Fractions of PSW-D fractions against E. coli (A),

E. aerogenes (B), S. aureus (C), and M. luteus (D). For (A) and (B), the positive control contains $300 \mu \mathrm{g}$ of tetracycline while for (C) and (D) the positive control contains $300 \mu \mathrm{g}$ chloramphenicol. Negative control contains $300 \mu \mathrm{g}$ of DMSO. Each disc with extract and fraction contains $\mathbf{3 0 0} \boldsymbol{\mu g}$ sample

Antibacterial screening of preparative the most active fractions PSW-W-D and PSW-D-F TLC-purified fractions. Separated components of were screened again for antibacterial activity.

Table 3: Average Antibacterial Activity of Separated Components of the Most Active Fraction of PSW-D and PSW-W

\begin{tabular}{|c|c|c|c|c|c|}
\hline & \multicolumn{5}{|c|}{ Zone of Inhibition in mm (Ave. per 3 trials) } \\
\hline & Sample & E. coli & E. aerogenes & M. luteus & S. aureus \\
\hline \multirow[t]{10}{*}{ PSW-D-F } & PSW-D-F-1 & N.A. & $2.67 \pm 0.00$ & N.A. & N.A. \\
\hline & PSW-D-F-2 & N.A. & N.A. & N.A. & N.A. \\
\hline & PSW-D-F-3 & N.A. & N.A. & N.A. & N.A. \\
\hline & PSW-D-F-4 & $6.67 \pm 5.77$ & $19.00 \pm 1.73$ & $14.00 \pm 1.00$ & $3.00 \pm 0.00$ \\
\hline & PSW-D-F-5 & N.A. & N.A. & N.A. & $2.33 \pm 0.00$ \\
\hline & PSW-D-F-6 & N.A. & $11.33 \pm 1.53$ & N.A. & N.A. \\
\hline & PSW-D-F-7 & $11.00 \pm 1.00$ & $18.67 \pm 3.06$ & $21.33 \pm 2.31$ & $7.00 \pm 6.08$ \\
\hline & PSW-D-F-8 & N.A. & $11.00 \pm 3.61$ & $24.00 \pm 5.29$ & $7.00 \pm 6.56$ \\
\hline & PSW-D-F-9 & $17.33 \pm 2.52$ & $20.67 \pm 1.15$ & $21.50 \pm 1.50$ & $26.33 \pm 4.93$ \\
\hline & PSW-D-F-10 & N.A. & $8.33 \pm 7.37$ & $13.65 \pm 1.10$ & $15.00 \pm 5.00$ \\
\hline \multirow[t]{15}{*}{ PSW-W-D } & PSW-W-D-1 & N.A. & $13.00 \pm 3.46$ & N.A. & N.A. \\
\hline & PSW-W-D-2 & N.A. & $7.00 \pm 6.24$ & N.A. & $5.33 \pm 4.62$ \\
\hline & PSW-W-D-3 & N.A. & $2.67 \pm 0.00$ & N.A. & N.A. \\
\hline & PSW-W-D-4 & $14.33 \pm 0.58$ & $25.67 \pm 3.79$ & N.A. & $22.33 \pm 1.53$ \\
\hline & PSW-W-D-5 & $17.33 \pm 4.62$ & $21.67 \pm 2.08$ & $20.33 \pm 10.17$ & $26.33 \pm 3.21$ \\
\hline & PSW-W-D-6 & $16.00 \pm 4.00$ & $22.33 \pm 3.51$ & $15.00 \pm 1.00$ & $21.33 \pm 1.15$ \\
\hline & PSW-W-D-7 & $2.67 \pm 0.00$ & $8.00 \pm 0.00$ & $9.50 \pm 1.00$ & $9.67 \pm 0.58$ \\
\hline & PSW-W-D-8 & $12.00 \pm 4.00$ & $20.67 \pm 2.31$ & $10.33 \pm 1.00$ & $17.67 \pm 7.51$ \\
\hline & PSW-W-D-9 & $15.33 \pm 1.53$ & $21.00 \pm 3.61$ & $24.00 \pm 1.00$ & $19.33 \pm 1.15$ \\
\hline & PSW-W-D-10 & N.A. & N.A. & $3.00 \pm 0.00$ & N.A. \\
\hline & PSW-W-D-11 & N.A. & N.A. & N.A. & N.A. \\
\hline & PSW-W-D-12 & N.A. & N.A. & N.A. & N.A. \\
\hline & PSW-W-D-13 & $21.33 \pm 2.31$ & $21.33 \pm 1.15$ & $23.00 \pm 2.00$ & $23.00 \pm 1.73$ \\
\hline & PSW-W-D-14 & $8.33 \pm 0.58$ & $9.33 \pm 2.52$ & $13.33 \pm 0.29$ & N.A. \\
\hline & PSW-W-D-15 & N.A. & N.A. & N.A. & N.A. \\
\hline
\end{tabular}

${ }^{*}$ N.A. = no activity.

${ }^{* *}$ Chloramphenicol $(10 \mathrm{mg} / \mathrm{mL})$ and tetracycline $(10 \mathrm{mg} / \mathrm{mL})$ were used as positive controls for Gram-positive and Gram-negative bacteria, respectively. 
The isolated PSW-D-F-9 and PSW-W-D13 exhibited the highest antibacterial activity. Both components were characterized via phytochemical screening. fractions. Isolated component, PSW-D-F-9 and PSW-W-D-13 were subjected to five phytochemical screening tests by thin layer chromatography. Presence of the bioactive components in the fraction and the isolated bands are shown on Table 4.

Phytochemical analyses of most active

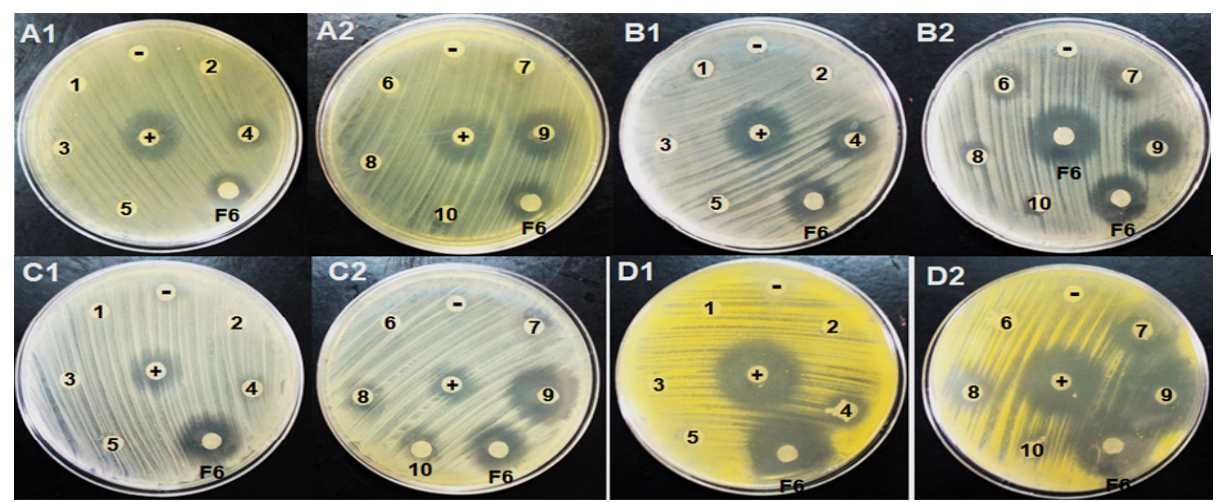

Fig. 4. Kirby-Bauer Assay Plates of Isolated Components of PSW-D-F against E. coli (A1, A2),

E. aerogenes (B1, B2), S. aureus (C1, C2), and M. Iuteus (D1, D2). For (A1), (A2), (B1) and (B2), the positive control contains $300 \mu \mathrm{g}$ of tetracycline while for (C1), (C2), (D1) and (D2) the positive control contains $300 \mu \mathrm{g}$ chloramphenicol. Negative control contains $300 \mu \mathrm{g}$ of DMSO. Each disc with extract and fraction contains $300 \mu \mathrm{g}$ sample

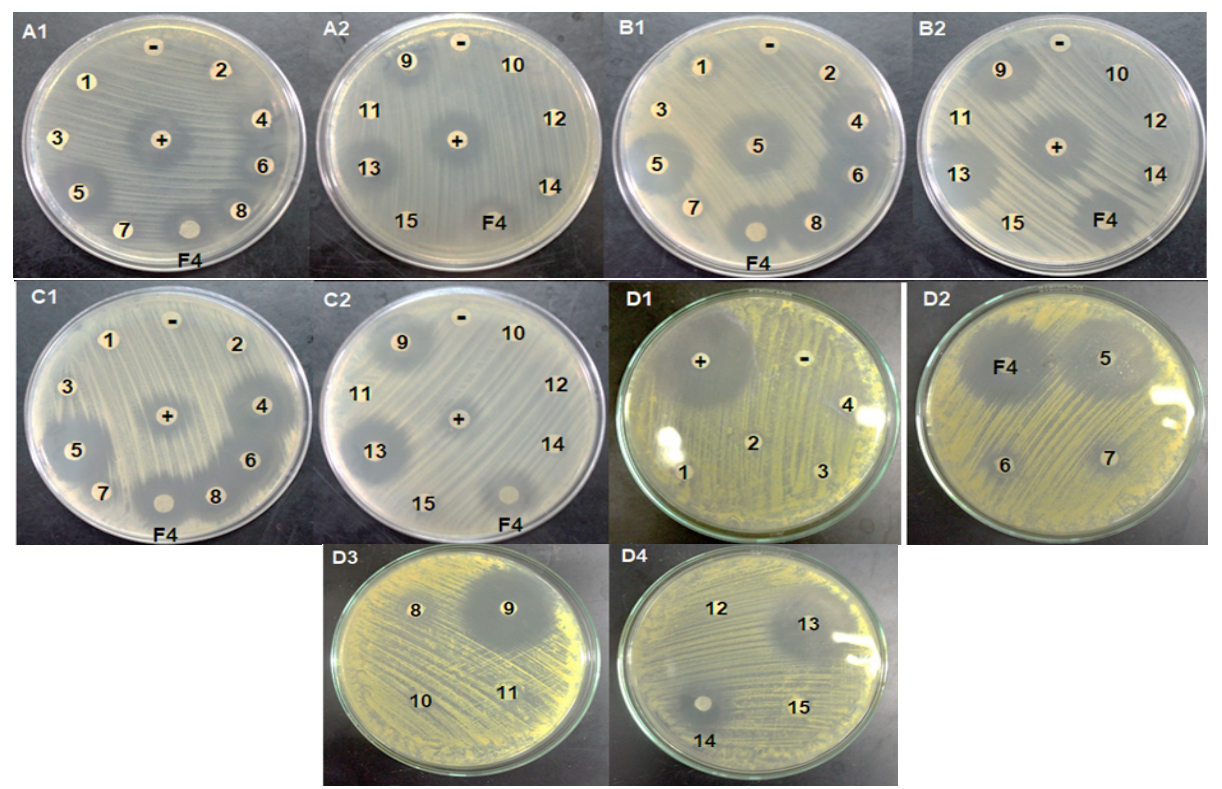

Fig. 5. Kirby-Bauer Assay Plates of Isolated Components of PSW-W-D against E. coli (A1, A2), E. aerogenes (B1, B2), S. aureus (C1, C2), and M. luteus (D1, D2, D3, D4). For (A1), (A2), (B1) and (B2), the positive control contains $300 \mu \mathrm{g}$ of tetracycline while for (C1), (C2), (D1), (D2), (D3) and (D4) the positive control contains $300 \mu \mathrm{g}$ chloramphenicol. Negative control contains $300 \mu \mathrm{g}$ of DMSO. Each disc with extract and fraction contains $300 \mu \mathrm{g}$ sample

Phytochemical screening revealed that the most active fraction from PSW-W contains alkaloids, higher alcohols, phenols, steroids and essential oils while the most active fraction from
PSW-D contains tannins, flavonoids, alkaloids, higher alcohols, phenols, steroids and essential oils. Both the isolated components (PSW-D-F-9 and 13), appeared to be composed of alkaloids. 
Table 4: Phytochemical screening by results. Legend: (+++): metabolite present in high intensity; (++): metabolite present in moderate intensity; (+): metabolite present in low intensity; (-): level of metabolite might be lower than detection limit or may not be present at all

\begin{tabular}{|c|c|c|c|c|c|c|}
\hline Phytochemicals & PSW-W Crude & PSW-W-D & PSW-D-F-9 & PSW-D Crude & PSW-D-F & PSW-W-D-13 \\
\hline Alkaloids (Dragendorff's reagent) & - & +++ & +++ & - & ++ & ++ \\
\hline Tannins (Potassium ferricyanide-ferric chloride) & ++ & - & - & + & + & - \\
\hline Indoles (Van Urk-Salkowski Test) & + & - & - & ++ & - & - \\
\hline Anthraquinones (Magnesium acetate) & - & - & - & - & - & - \\
\hline $\begin{array}{l}\text { Essential oils, Triterpenes, sterols } \\
\text { (Vanillin-Sulfuric Acid) }\end{array}$ & + & +++ & - & ++ & ++ & - \\
\hline
\end{tabular}

\section{DISCUSSION}

Preliminary antibacterial and antifungal analyses were conducted on the crude ethanolic extracts of PSW-W and PSW-D where all the crude extracts exhibited antibacterial activities. It was observed that the crude ethanolic extract from the wet season showed the strongest inhibition against $M$. luteus and exhibited higher average zone of inhibitions for all test organisms.

For the zones of inhibition of the isolated components of PSW-D-F, it can be observed that the crude fraction (PSW-D-F) has the highest activity against M.luteus and as for the isolated components, PSW-D-F-9 has the highest antibacterial activity against the four test organisms; M.luteus, S.aureus, E. coli and E. aerogenes. PSW-D-F-3 only showed activity against M.luteus while PSW-D-F-2 did not show any activity at all. PSW-D-F-5 only exhibited activity against $S$. Aureus. PSW-D-F-1 and PSW-D-F-6 only showed activity against the Gram-negative bacteria $E$. aerogenes which is very interesting because it exhibited activities on a less susceptible organism rather than with the Gram-positive bacteria. It is also remarkable how PSW-D-F-9 shows antibacterial activity against all the test organisms which could signify that the components within this extract encompass a broad spectrum of microorganisms.

For zones of inhibition of isolated components of PSW-W-D, PSW-W-D-13 was chosen to be characterized having similar results as PSW-D-F-9 with antibacterial activity against all the test organisms. PSW-W-D-11, PSW-W-D12 and PSW-W-D-15 did not exhibit any activity while other extracts showed significant activities to Gram-negative or Gram-positive bacteria.

The presence of wide range of phytochemical constituent indicates that the plant could be used in a multitude of ways, which may be beneficial. An important part of natural products from plants, biomolecules and secondary metabolites usually exhibits some kind of biological activities. They could be used in the human therapy, veterinary, agriculture, scientific research and in countless other areas. The usefulness of plant materials medicinally is due to the presence of bioactive constituents such as alkaloids, tannins, flavonoids and phenolic compounds ${ }^{12}$.

Several compounds have been previously isolated from $P$. spicatus. The chloroform extract of the leaves afforded stigmasterol, glaucolide B, spicatolide A and B13. An antifungal cadinanolide from the leaf chloroform extract was found moderately active against Candida albicans and Aspergillus niger, with low toxicity against $S$. aureus, E. coli and $P$. aeruginosa ${ }^{14}$. From the leaf methanolic extract, spicatolide C, spicatocadinanolide A, piptocarphol isomers and a eudismane-type sesquiterpene were obtained as well ${ }^{15}$. Here, the isomeric mixture of piptocarphol isomers displayed the strongest activity against MCF7, HepG2 and MDA-MB-231 cell lines with $I_{50} 11.20,16.48$ and $14.71 \mu \mathrm{g} / \mathrm{mL}$. Two hirsutinolides (8,13-diacetyl-piptocarphol and 8-acetyl-13-O-ethyl-piptocarphol) and ursolic acid were isolated from the leaf ethanolic extracts of $P$. spicatus and were found to be active against Leishmania amazonensis, a parasite responsible for the disease Leishmaniasis ${ }^{16}$.

Environmental conditions affect the plant growth as well as the production of secondary metabolites. The difference in phytochemicals present in the plant samples collected at different seasons may suggest that seasonal variation affects the production of this plant constituents ${ }^{17}$. Other external factors may have interfered in the optimum production of plant metabolites and because of these, the secondary metabolites present in the 
sample vary, exhibiting different activities. Rainy season has positive impact on plant growth as well as the formation of alkaloids. Alkaloid synthesis increases with progressive maturity. It reaches to highest concentration at flowering stage ${ }^{18}$. It is observed in the phytochemical analysis that the wet season sample has greater intensity for the presence of alkaloids in comparison with the dry samples. The crude extracts on the other hand did not pass in the screening for alkaloids even though later analysis showed fractionated extracts are positive for such. The presence of all the secondary metabolites in the crude extracts could have mask some metabolites thus, they were unable to be detected. Highest concentration of polyphenols was found to be during the rainy season and lowest in summer. The stage of growth of the plant has an impact on phenolic contents. From the present study it is concluded that growth stages and seasons show effect on eco-physiological parameters. Favorable climatic conditions are believed to stimulate the secondary metabolite synthesis.

\section{CONCLUSION}

This is the first report of the antibacterial activity of the leaf ethanolic extracts of $P$. spicatus collected from Mt. Isarog, Camarines Sur, Philippines were demonstrated to be effective against both Gram-positive and Gram-negative bacteria. Phytochemical screening by TLC revealed that the most active fraction from PSW-W contains alkaloids, higher alcohols, phenols, steroids and essential oils while the most active fraction from PSW-D contains tannins, flavonoids, alkaloids, higher alcohols, phenols, steroids and essential oils. Further purification and characterization of the active compound/s from $P$. spicatus is recommended.

\section{ACKNOWLEDGEMENT}

The authors would like to acknowledge the support of the Department of Physical Sciences and Mathematics, College of Arts and Sciences, University of the Philippines Manila, by providing the facilities necessary to complete this project. This research was funded by the "University of the Philippines Creative and Research Scholarship Fund".

\section{Conflict of interest}

The authors declare no conflict of interest.

\section{REFERENCES}

1. Ross J; Normand S.L.; Wang Y.; Nallamothu B.K.; Lichtman J.H.; Krumholz H.M. Health Affairs., 2008, 27(6), 1707-1717.

2. Brown R. M.; Fernandez R.B.; Rivero C.; Buenviaje R.; Diesmos A. Mt. Isarog's Herpetological Wonders. Haring Ibon., 2001, July-August-September, 12-17.

3. Sharma K.;Dubey S. J Exp Sci., 2011, 2(10), 60-61.

4. Bunwong S.; Chantaranothai P. Thai For. Bull. (Bot.)., 2010, 38, 124-127.

5. Langenberger G.; Prigge V.; Martin K.; Belonias B.; Sauerborn J. Agroforest Syst., 2009, 76, 173-194.

6. Gomes A.; Das R.; Sarkhel S.; Mishra R.; Mukherjee S.; Bhattacharya S.; Gomes A. Indian J. Exp. Bio., 2010, 48, 865-878.

7. Lin C.C.; Kan W.S. American J Chinese Med., 1990, 18(1-2), 35-43.

8. Odonne G.; Bourdy G.; Castillo D.; Estevez Y.; Lancha-Tangoa A.; Alban-Castillo J.; Deharo E.; Rojas R.; Stien D.; Sauvain M. J. Ethnopharm., 2009, 126(2009), 149-158.

9. Bringmann G.; Rückert M.; Messer K.; Schupp
O.; Louis A. M. J Chrom A., 1999, 837(1-2), 267-272.

10. Kamba A.S.; Hassan L.G. Afr J Pharm Pharmacol., 2010, 4(9), 645-652.

11. Aguinaldo A.M.; Espeso E.I.; Guevara B.Q.; Nonato MG. Philippines: UST Publishing House., 2005.

12. Lalitha P.; Jayanthi P. Asian J Plant Sci Res., 2012, 2(2), 115-122.

13. Ragasa C.Y.; Padolina W.G.; Yamauchi T.; Otsuka H.; Yamasaki K.; Satoh T. Phytochemistry., 1993, 33(3), 627-629.

14. Ragasa C.Y.; Rideout J. A. Chem. Pharm. Bull., 2001, 49(10), 1359-1361.

15. Issa H.H.; Chang S.M.; Yang Y.L.; Chang F.R.; Wu Y.C. Chem. Pharm. Bull., 2006, 54(11), 1599-1601.

16. Odonne G.; Herbette G.; Eparvier V; Bourdy G.;Rojas R.; Sauvian M.; Stien D. J. Ethnopharm., 2011, 137(2011), 875-879.

17. Heera L; Kasera, P. Int Res J Plant Sci., 2012, 3(8), 174-180.

18. Kale V.S. Asia J Exp Biol Sci., 2010, 2010, 50-53. 